\title{
Experimentally measured morphology of biomass burning aerosol and its impacts on CCN ability
}

\author{
M. Giordano ${ }^{1,2}$, C. Espinoza ${ }^{1,2}$, and A. Asa-Awuku ${ }^{1,2}$ \\ ${ }^{1}$ Department of Chemical and Environmental Engineering, University of California - Riverside, Riverside, California, USA \\ ${ }^{2}$ College of Engineering - Center for Environmental Research and Technology (CE-CERT), Riverside, California, USA
}

Correspondence to: A. Asa-Awuku (akua@engr.ucr.edu)

Received: 10 April 2014 - Published in Atmos. Chem. Phys. Discuss.: 16 May 2014

Revised: 3 September 2014 - Accepted: 8 September 2014 - Published: 20 February 2015

\begin{abstract}
This study examines the morphological properties of freshly emitted and atmospherically aged aerosols from biomass burning. The impacts of particle morphology assumptions on hygroscopic predictions are examined. Chamber experiments were conducted at the University of California, Riverside, Center for Environmental Research and Technology (CE-CERT) atmospheric processes lab using two biomass fuel sources: manzanita and chamise. Morphological data was obtained through the use of an aerosol particle mass analyzer (APM), scanning mobility particle sizer (SMPS) system and transmission electron microscope (TEM). Data from these instruments was used to calculate both a dynamic shape factor and a fractal-like dimension for the biomass burning emissions. This data was then used with $\kappa$-Köhler theory to adjust the calculated hygroscopicity for experimentally determined morphological characteristics of the aerosol. Laboratory measurement of biomass burning aerosol from two chaparral fuels show that particles are nonspherical with dynamic shape factors greater than 1.15 for aerosol sizes relevant to cloud condensation nuclei $(\mathrm{CCN})$ activation. Accounting for particle morphology can shift the hygroscopicity parameter by 0.15 or more. To our knowledge, this work provides the first laboratory chamber measurements of morphological characteristics for biomass burning cloud condensation nuclei and provides experimental particle shape evidence to support the variation in reported hygroscopicities of the complex aerosol.
\end{abstract}

\section{Introduction}

Aerosols have important health effects, affect regional visibility, are a key factor in the earth's climate via radiative forcing mechanisms, and play a vital role in atmospheric chemistry (Seaton et al., 1995; Haywood and Boucher, 2000; Ramanathan et al., 2001; Pöschl, 2005; Forster et al., 2007). For all impacts, particle composition and size are important. Particles are ubiquitous but can be nonuniform and nonspherical. As such, a number of instruments exist to measure these critical aerosol properties. One property that remains difficult to characterize through conventional techniques is particle morphology. Morphology is used here as a term to describe the shape of a 3-dimensional particle and has a direct impact on particle size measurements (DeCarlo et al., 2004). The true volume of a particle is difficult to accurately measure without knowledge of the particle morphology. Reducing uncertainties in particle morphology will increase the accuracy of characterizations and parameterizations that rely on knowing the true volume of a particle, e.g., particle density and hygroscopicity.

Biomass burning emissions are a major source of nonuniform and nonspherical complex aerosol emissions (2$5 \mathrm{Pg} \mathrm{C} \mathrm{yr}^{-1}$ ) to the atmosphere (Crutzen and Andreae, 1990; Andreae et al., 2004; Reid et al., 2005; van der Werf et al., 2006). Both the developed and developing world are subject to biomass burning events through agricultural burning, wildfires, and domestic burning applications (Forster et al., 2007). The aerosol formed during biomass burning events is a complex mixture of volatile, semivolatile, and nonvolatile components that are able to seed clouds, modify cloud properties, and indirectly impact radiative forcing (Forster et al., 2007; 
Reutter et al., 2009; Liu and Wang, 2010). The impact of a potential wildfire or prescribed burn depends on the fuel type, the burning regime (e.g., smoldering, flaming, or mixed), and the aging time of the atmospheric emissions. This work further explores the role of biomass burning aerosol as cloud condensation nuclei $(\mathrm{CCN})$. We obtain information about the shape and true volume of biomass burning particles using a semicontinuous method to investigate the impact of particle size, changes in shape that occur during the evolution of photochemical aging and changes in perceived hygroscopicity as a result of particle volume and sizing assumptions. A large portion of this study presents data on fresh biomass burning aerosol that is most applicable near the point of emission. However, the data and conclusions that are presented should be noted whenever an estimation of the climate impacts of biomass burning aerosols are discussed.

\section{Theoretical considerations}

\subsection{Biomass burning cloud condensation nuclei}

Several recent works on biomass burning aerosol have focused on their ability to act as CCN (e.g., Novakov and Corrigan, 1996; Martins et al., 2009; Petters et al., 2009; Carrico et al., 2010; Rose et al., 2010, 2011; Hennigan et al., 2011; Engelhart et al., 2012; Giordano et al., 2013; Lathem et al., 2013; Martin et al., 2013; Yokelson et al., 2009). The $\mathrm{CCN}$ ability of inorganic compounds can be described well by classical Köhler theory (Köhler, 1936). The theory has since been expanded to better model organic/inorganic mixed particles with varying degrees of accuracy and complexity (e.g., Shulman et al., 1996; Raymond and Pandis, 2002). One extension, $\kappa$-Köhler theory, has become a common method for reporting CCN ability and estimating particle hygroscopicity. Its popularity is due to its empirical grounding, ease of understanding, ability to represent organic/inorganic mixed particles and translate to both the sub- and supersaturated regimes. This has led to a large body of published $\kappa$ Köhler theory values. The $\kappa$ parameterization of hygroscopicity posits that particle diameter and the supersaturation at the point of activation effectively capture CCN ability (Petters and Kreidenweis, 2007):

$\kappa=\frac{4 A^{3}}{27 D_{\mathrm{d}}^{3} \ln ^{2} S_{\mathrm{c}}} ;$ where $A=\frac{4 \sigma_{\mathrm{s} / \mathrm{a}} M_{\mathrm{w}}}{\mathrm{RT} \rho_{\mathrm{w}}}$,

where $\rho_{\mathrm{W}}$ is the density of water, $M_{\mathrm{w}}$ is the molecular weight of water, $\sigma_{\mathrm{s} / \mathrm{a}}$ is the surface tension of the solution-air interface, $R$ is the universal gas constant, $T$ is the temperature, $D_{\mathrm{d}}$ is the dry particle diameter, and $S_{\mathrm{c}}$ is the critical supersaturation required to activate a particle with size $D_{\mathrm{d}}$. In practice, $D_{\mathrm{d}}$ is generally the measured electrical mobility diameter and is calculated as the $50 \%$ efficiency for which half of all particles activate at $s_{\mathrm{c}}$, the instrument supersaturation. In the derivation of $\kappa$-Köhler theory, $D_{\mathrm{d}}^{3}$ actually stands in for the volume of the particle being activated. A main focus of this study are the implications of treating the electrical mobility diameter as the volume equivalent diameter. From Eq. (1), $\kappa$ is interpolated using a linear regression of experimental $D_{\mathrm{d}}$ and calibrated $s_{\mathrm{c}}$.

Thus, the CCN activity can be represented by a single hygroscopicity parameter, $\kappa$. A range of $\kappa$ biomass burning literature values has been reported. Multiple factors affect this range. Different fuels can have a wide variability in $\mathrm{CCN}$ activity. The particles can be very nonhygroscopic (e.g., $\kappa<0.1$ for various softwoods) to very hygroscopic (e.g., $\kappa>0.5$ for sage and sawgrass) (Petters et al., 2009; Carrico et al., 2010). Differences in burning conditions contribute to the range of $\kappa$. Additionally, the oxidative aging of these emissions can affect the observed $\kappa$ values (Hennigan et al., 2011; Engelhart et al., 2012). The presence of surface-active compounds can also affect the range of $\kappa$ (Giordano et al., 2013).

The derivation of $\kappa$-Köhler theory, as stated in Eq. (1), is chosen here because it a computationally inexpensive form of the theory to implement and is widely used. The derivation of $\kappa$-Köhler theory in Eq. (1) applies a few assumptions (that do not necessarily apply to all derivations of $\kappa$-Köhler theory). First, ideal droplet water activity conditions are assumed when the growing cloud droplet exists as an aqueous solution and all available solute is dissolved. Second, $\kappa$-Köhler theory applies the ideal surface tension of water, $\sigma_{\mathrm{s} / \mathrm{a}}=0.072 \mathrm{~J} \mathrm{~m}^{-2}$. Third, and most important for application to biomass burning, the diameter of the particle cubed, $D_{\mathrm{d}}^{3}$, is assumed to estimate the volume of a spherical particle. A number of studies have investigated the applicability of the first two assumptions and come to varying conclusions on their importance. Martin et al. (2013) did observe that nonspherical particles can exist in biomass burning plumes and their presence can lead to an underestimation of $\kappa$. Here we present the same conclusions but the work presented here differs in a number of important ways from the work of Martin et al. The experimental setup used in Martin et al. was a clever way to determine that the particles were nonspherical but was not able to measure the degree of nonsphericity. Both this work and Martin et al. observed the effect that aging has on particle morphology and how that impacts $\kappa$, but here we are able to quantify the changes in morphology through empirical constructs such as fractal-like dimension. It remains that the magnitude of particle nonsphericity and its effect on hygroscopicity has only been theoretically manipulated and not experimentally measured, especially as a function of particle aging (Dusek et al., 2011). Here we provide simultaneous morphological and hygroscopicity measurements of fresh and aged biomass aerosol. These measurements together provide a more accurate parameterization of particle hygroscopicity. 


\subsection{Volume equivalent and electrical mobility diameters}

$\mathrm{CCN}$ activity measurements require either mass or volume information in addition to droplet activation data. Particle diameter alone can introduce $84-96 \%$ variation in CCN concentrations (Dusek et al., 2006). Particle volume information is commonly obtained from mobility particle sizing instrumentation and is combined with a cloud condensation nuclei counter (CCNC). This experimental method selects the electrical mobility diameter of a particle. The mobilityselected particle then flows to the supersaturated column of the CCNC where, if above a critical size, it activates to form a cloud droplet. When combined with $\kappa$-Köhler theory, the method assumes that a particle's electrical mobility is equivalent to its volume equivalent diameter. For a spherical particle this is true: the mobility diameter equals the volume-equivalent diameter. However, for nonspherical particles, electrical mobility diameter deviates from the volume equivalent diameter. The phenomenon has also been observed in CCN experiments using mass-selected particles measured with a Kanomax APM (aerosol particle mass analyzer; Kuwata and Kondo, 2009). The volume equivalent diameter $\left(d_{\mathrm{ve}}\right)$ is defined as the diameter of a spherical particle of the same volume as the particle of interest (Baron and Willeke, 2001). For a nonspherical particle, $d_{\mathrm{ve}}$ is the diameter of the particle if it were compacted or melted to form a sphere while preserving internal void spaces (empty regions of the particle that are isolated from the surrounding gas).The electrical mobility diameter, $d_{\mathrm{m}}$, can be measured with a differential mobility analyzer (DMA) and is defined as the diameter of a sphere with the same migration velocity in a constant electric field as the considered particle (Knutson and Whitby, 1975). A force balance occurs in the annular region of the DMA to mobility-select a certain "size" particle. The particle is first charged and flown into an annulus with a constant electric field being applied between the inner and outer walls. As the particle moves in the electric field, the charge on the particle is attracted toward the inner annular wall. A drag force between the particle and gas is equal and opposite to the electrical force when the particle reaches a terminal migration velocity. Careful design of the annulus allows for a particle of a desired electrical mobility to exit the DMA in a monodisperse size stream.

Assuming a particle and its volume equivalent sphere have the same charge, the relationship between the two diameters is as follows:

$\frac{d_{\mathrm{m}}}{C_{\mathrm{C}}\left(d_{\mathrm{m}}\right)}=\frac{d_{\mathrm{ve}} \chi}{C_{\mathrm{C}}\left(d_{\mathrm{ve}}\right)}$,

where $C_{\mathrm{C}}$ is the Cunningham slip correction factor and $\chi$ is the dynamic shape factor. The slip correction factor used in the calculation of Eq. (2) is given in Seinfeld and Pan- dis (2006) as

$C_{\mathrm{C}}=1+\frac{2 \lambda}{D}\left[\alpha+\beta \exp \left(-\frac{\gamma D}{2 \lambda}\right)\right]$,

where $D$ is the diameter of the particle, $\lambda$ is the mean free path of the suspending fluid, and $\alpha, \beta$, and $\gamma$ are empirical constants. The empirical constants used in this study are given in Allen and Raabe (1982). The dynamic shape factor is a correction to account for the increased drag on a nonspherical particle (Fuchs, 1964). The shape factor is equal to one for a sphere and can be greater than one for nonspherical particles. The flow regime of the suspending fluid relative to the particle dictates the nature of the forces acting on the particle. Hence, both $C_{\mathrm{C}}$ and $\chi$ are functions of the Knudsen number. The flow regime here is in the transition regime because both particle sizing and the CCNC commonly operate near standard ambient temperature and pressure (approximately $298 \mathrm{~K}, 1 \mathrm{~atm}$ ) and the particles of interest as CCN are between 10 and $200 \mathrm{~nm}$. This introduces an added level of complexity to volume calculations, as the dynamic shape factor behavior is more readily available in the continuum and free molecular regimes (Dahneke, 1973a, b; Kousaka et al., 1996; Baron et al., 2001). However, other work on nonspherical particles and their dynamic shape factors have assumed that the shape factor in the transition regime is approximately equal to the shape factor in the free-molecular regime (DeCarlo et al., 2004). The analysis presented here also makes this assumption. Our analysis also neglects particle orientation effects on the shape factor. Because $\chi$ can be greater than 1 for nonspherical particles, the use of electrical mobility for volume measurement will likely overpredict particle volume. An overprediction in particle volume in Eq. (1) will underestimate calculated $\kappa$ values; thus, misrepresenting the cloud forming ability of nonspherical aerosols.

It should be noted that calculation of the volume equivalent diameter is possible without explicit knowledge of the shape factor. If the density of the material is known, then the volume equivalent diameter can be determined from measuring the mass of a given particle (DeCarlo et al., 2004; Kuwata and Kondo, 2009). The uniqueness of this study is the experimental observation of the shape factor to compensate for the unknown density of the complex material from biomass burning aerosols.

\subsection{Fractal and fractal-like dimensions}

Combustion processes often generate aggregates of small $(d<10-30 \mathrm{~nm})$ particles. The fractal dimension $\left(D_{\mathrm{f}}\right)$ is a semiempirical relationship often used to describe aggregates. $D_{\mathrm{f}}$ is defined as the relationship between the number of primary particles in an aggregate to the aggregate's radius of gyration. The relation can be written as a power law expression (Mandelbrot, 1982):

$N=C\left(\frac{R_{\mathrm{g}}}{a}\right)^{D_{\mathrm{f}}}$, 
where $N$ is the number of primary particles in the aggregate, $R_{\mathrm{g}}$ is the radius of gyration of the aggregate, $a$ is the radius of the primary particles, and $C$ is a constant. Park et al. (2003) use this relationship with the assumption that the primary particle diameters are approximately constant to show that $N$ then varies proportionately to particle mass. Park et al. also assume that the radius of gyration is linearly proportional to the mobility diameter in the continuum and free-molecular regimes (Schmidt-Ott et al., 1990) to define a "fractal-like" dimension, here referred to as $D_{\mathrm{f}}^{\prime}$ :

$m=C^{\prime} D_{\mathrm{m}}^{D_{\mathrm{f}}^{\prime}}$,

where $m$ is the mass of the aggregate. Here, a $D_{\mathrm{f}}^{\prime}$ of 3 implies a spherical particle while $D_{\mathrm{f}}^{\prime}<3$ indicates a nonspherical particle. This relationship, and its analogue in density, is directly applicable to data obtained from the Kanomax APM. Park et al. used APM data to determine the fractal-like dimension of diesel exhaust particles. They obtained fractal-like dimensions of $2.33<D_{\mathrm{f}}^{\prime}<2.84$ depending on engine load. Work done by Nakao et al. (2011) used this relationship to show SOA (secondary organic aerosol) formation from diesel exhaust has similar $D_{\mathrm{f}}^{\prime}$. Zhang et al. (2008) exposed flamegenerated soot to subsaturated sulfuric acid vapor and obtained a fresh (unexposed) $D_{\mathrm{f}}^{\prime}$ of 2.1 and an aged (exposed) $D_{\mathrm{f}}^{\prime}$ of 2.8 .

In this work, we obtain information about the shape and true volume of biomass burning particles using a semicontinuous method. We do this for both freshly emitted and photochemically aged emissions. We provide evidence to support the work of others that demonstrate that (1) the particles emitted are nonspherical, (2) the degree of nonsphericity changes with photochemical aging, and (3) using the true volume equivalent diameter to calculate $\kappa$ greatly shifts the predicted hygroscopicity. We also discuss how the limitations of the current methods for measuring particle volume affects $\mathrm{CCN}$ measurements.

\section{Experimental methods and instrumentation}

A series of biomass burning experiments were carried out at the University of California, Riverside, College of Engineering - Center for Environmental Research and Technology (UCR CE-CERT) atmospheric processes lab from the spring to the summer of 2013. Two shrubs common to the California chaparral biome, chamise (Adenostoma fasciculatum) and manzanita (Arctostaphylos glandulosa), were burned in an outdoor wood-burning stove. Both fuels were collected on Bureau of Land Management land near the San Bernardino National Forest (approximately $33.84^{\circ},-116.88^{\circ}$ and the surrounding area). The collection site is approximately 3600-3900 feet in elevation. Chaparral species such as chamise, manzanita, scrub oak, and ceanothus surround the area. Both manzanita and chamise burned in the flaming regime. The flame-integrated modified combustion efficiencies (MCE) of both fuels were greater than 0.97 (where $\mathrm{MCE} \equiv \frac{\Delta \mathrm{CO}_{2}}{\left(\Delta \mathrm{CO}_{2}+\Delta \mathrm{CO}\right)}$; Ward and Hao, 1991).

A sample line from the stack of the stove drew smoke from the fire and diluted it with a venturi tube injection system. The diluted sample was then injected into a $12 \mathrm{~m}^{3}$ Teflon chamber to a final particle concentration $\sim 100 \mu \mathrm{g} \mathrm{m}^{-3}$. The chamber concentration is within range of ambient and plumelike concentrations also used in previous chamber studies (Hennigan et al., 2011). The sample was injected with a $10: 1$ total flow to sample flow ratio. As short of a copper transfer line as possible (approximately $7 \mathrm{~m}$ in length) was used for the smoke injection. The enclosure is surrounded by $170 \mathrm{ul}-$ traviolet (UV) lights with peak intensity of $350 \mathrm{~nm}(350 \mathrm{BL}$, Sylvania ${ }^{\circledR}$ ). UV lights were turned on $1 \mathrm{~h}$ after injection to promote photochemistry and remained on until the experiment concluded. The chamber was flushed and filled with filtered air prior to injection. The temperature of the chamber ranged approximately from 20 to $27^{\circ} \mathrm{C}$ during the experiments. The experiment was operated until the chamber was empty (up to $6 \mathrm{~h}$ ). This series of chamber burns produced particle number, size, and volume data similar to that of ambient studies and previous aged biomass burning studies conducted at CE-CERT (Hennigan et al., 2011; Giordano et al., 2013).

Scanning mobility CCN analysis (SMCA) was used to obtain fast size-resolved CCN activity of the aging system (Moore et al., 2010). The sampled aerosol was sizeclassified using a scanning mobility particle sizer (SMPS, TSI 3080/3081). The monodisperse stream from the classifier was split and one stream entered a condensation particle counter (TSI 3772) while the other stream was sampled with a DMT (Droplet Measurement Technologies) continuous flow streamwise thermal gradient chamber $\mathrm{CCN}$ counter (CCNC) (Roberts and Nenes, 2005; Rose et al., 2008). The CCNC instrument was operated at a 10:1 sheath-to-aerosol ratio with a sample flow of $0.5 \mathrm{~L} \mathrm{~min}^{-1}$. The total concentration $(\mathrm{CN})$ of sized particles measured by the CPC (condensation particle counter) determined the ratio of $\mathrm{CCN} / \mathrm{CN}$. For each supersaturation, $s_{\mathrm{c}}$, the activation diameter, $D_{\mathrm{d}}$, was defined as the diameter for which $\mathrm{CCN} / \mathrm{CN}=0.5$. The experimental setup was calibrated with ammonium sulfate $\left(\left(\mathrm{NH}_{4}\right)_{2} \mathrm{SO}_{4}\right)$ aerosol. $\mathrm{CCNC}$ calibration information is provided in Table A1.

A schematic of the experimental setup to measure particle mass and calculate particle effective density is shown in Fig. 1. Particles were selected by mass in the Kanomax APM, then sized by electrical mobility in a downstream DMA column, and the DMA exit stream was split between the CPC (TSI 3760A) and an electrostatic TEM (transmission electron microscope) precipitator (FHNW TEM sampler). The APM-DMA setup was used for improved time resolution over the DMA-APM setup (McMurry et al., 2002; Khalizov et al., 2009; Xue et al., 2009). The system is described in more detail in Malloy et al. (2009). Here, the APM selected three different particle masses between the (spherical, unit 


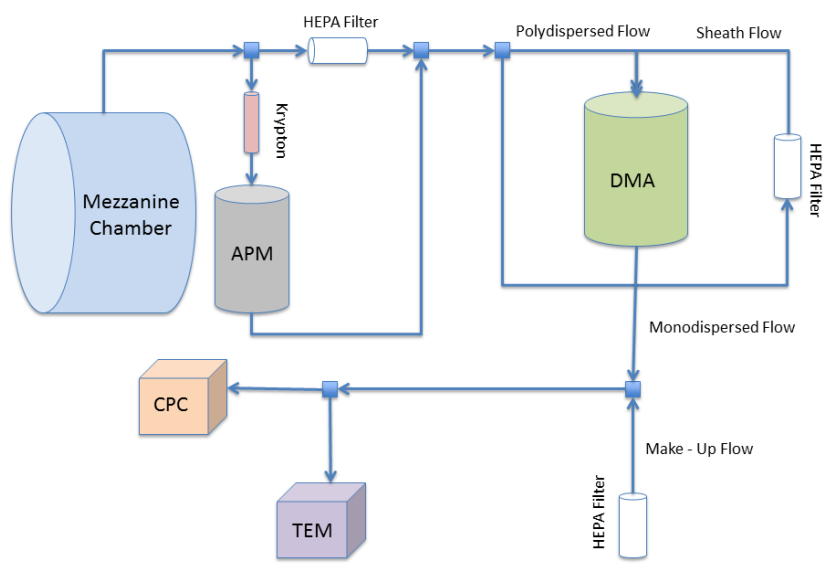

Figure 1. Schematic of the APM-DMA-TEM setup.

density equivalent) 50 and $100 \mathrm{~nm}$ particle size range. TEM grids were used to collect three masses of particles relevant to $\mathrm{CCN}$ activation, corresponding to approximately 50,75 , and $100 \mathrm{~nm}$ particles (assuming unit density). Using the effective density analogue of Eq. (5), the fractal-like dimension was obtained by fitting the power function (Park et al., 2003; Xue et al., 2009; Nakao et al., 2011):

$\rho_{\mathrm{eff}}=C d_{\mathrm{m}}^{D_{\mathrm{f}}^{\prime}-3}$,

where $\rho_{\text {eff }}$ is the effective density of particles, $C$ a constant, $d_{\mathrm{m}}$ is the mobility diameter of the particles, and $D_{\mathrm{f}}^{\prime}$ the fractal-like dimension. For reference, the effective density of a particle is related to the material density of a particle by

$m_{\mathrm{p}}=\frac{\pi}{6} \rho_{\mathrm{m}} d_{\mathrm{ve}}^{3}=\frac{\pi}{6} \rho_{\mathrm{eff}} d_{\mathrm{m}}^{3}$,

where $m_{\mathrm{p}}$ is the mass of the particle and $\rho_{\mathrm{m}}$ is the density of the material comprising the aerosol. During the beginning and the end of the experiment, the TEM precipitator was turned on. The APM was operated in a single mass selection until the charge across the TEM grid was $60 \mathrm{pA}$, indicating a sufficient capture of particles. After an experiment, the TEM grids were stored in a grid holder away from heat and light. The grids were analyzed using a Philips Tecnai 12 transmission electron microscope.

The pictures of the particles obtained from the TEM were further analyzed using the freeware image analysis program ImageJ (http://imagej.nih.gov/ij/). The shape factor, $\chi$, is determined from mobility diameter data and a volume calculation of each particle. The mean volume of the agglomerates for each APM mass selection was calculated as follows (Park et al., 2004):

$\bar{V}=\frac{\sum_{i} N_{i} \frac{\pi}{6} \bar{d}_{\mathrm{p}}^{3}}{n}$,

where $N$ is the number of primary particles in the agglomerate, $d_{\mathrm{p}}$ is the mean primary particle diameter, and $n$ the num- ber of agglomerates. By using two-dimensional projected images of three-dimensional objects from the TEM, previous studies have demonstrated that the projected area can be used to calculate $N$ or $R_{\mathrm{g}}$ in fractal agglomerates (e.g., Meakin et al., 1989; Koylu et al., 1995):

$N=k_{\mathrm{a}}\left(\frac{A_{\mathrm{a}}}{A_{\mathrm{p}}}\right)^{\alpha}$,

where $A_{\mathrm{a}}$ is the projected area of the agglomerate, $A_{\mathrm{p}}$ is the mean projected area of primary particles, $k_{\mathrm{a}}$ is a constant, and $\alpha$ is a projected area exponent. Numerical simulations have been used to calculate the empirical factors of Eq. (9), $k_{\mathrm{a}}$ and $\alpha$. In this study, we use the values of Oh and Sorensen (1997) who found that $\alpha=1.19$ and $k_{\mathrm{a}}=1.81$ well described the agglomerates whose primary particles were allowed to overlap. $A_{\mathrm{a}}, A_{\mathrm{p}}$, and $d_{\mathrm{p}}$ were determined through image analysis using ImageJ. Figure 2 shows how the three values were selected.

Once the mean volume of an aggregate at a certain mass was found with the above analysis, the diameter of the sphere with that volume was used as the volume-equivalent diameter for that particle. The above analysis is only applied directly to freshly emitted particles. It does contain the assumption that condensing material forms a uniform layer of material over the primary particles; i.e., that there is no preferential partitioning of condensing material. The mean peak mobility diameter measured from the SMPS during the collection of the TEM grid was used as the mobility diameter for application in Eq. (2).

\section{Results and discussion}

\subsection{Morphology of freshly emitted biomass burning aerosol}

The APM-SMPS-TEM system (Fig. 1) measured the freshly emitted properties of biomass burning aerosol. The TEM grids were then photographed and analyzed as illustrated in Fig. 2. The primary particle diameter was both calculated from the projected area of the primary particles $\left(A=d^{2} \cdot \pi / 4\right)$ and measured directly. Direct measurement was done by measuring the average length of multiple lines drawn from the edges through the center of a primary particle. If the directly measured and calculated diameters deviated more than $50 \%$, then the calculated value from the projected area was used and is reported here.

To measure the area and diameter of primary particles, only particles clearly distinguishable were selected for analysis. This usually meant that particles on the ends of fractal chains were selected as opposed to those in the center of the agglomerates. Previous work on flame-generated agglomerates has shown that the primary particle diameters follow a normal distribution with a mean between 28.5 and $34.4 \mathrm{~nm}$ (Koylu and Faeth, 1992; Lee et al., 2001). Figure 3 shows 


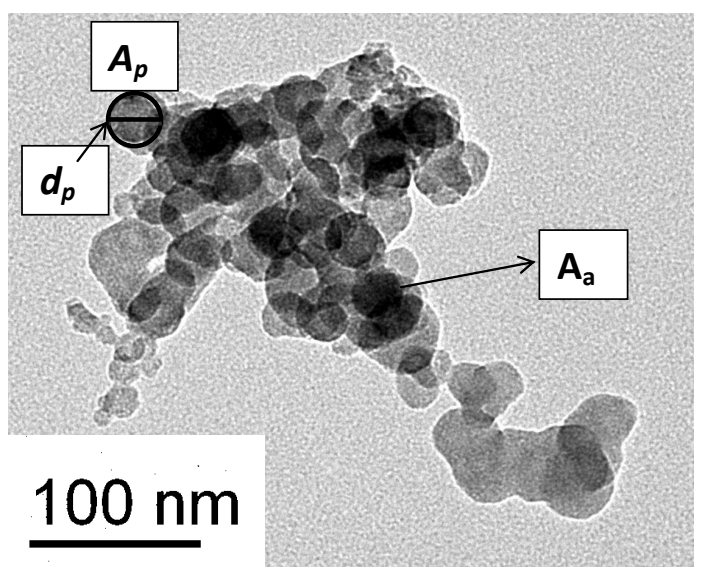

Figure 2. The three measured parameters from the TEM pictures used in this study: the primary particle projected area $\left(A_{\mathrm{p}}\right)$, primary particle diameter $\left(d_{\mathrm{p}}\right)$, and the projected area of the particle $\left(A_{\mathrm{a}}\right)$.

the primary particle diameter distribution from particles at the three selected masses from the APM-SMPS system. The total number of individual primary particles analyzed is 475 . The data is fit with a normal Gaussian distribution whose mean lies at $25.7 \pm 2.1 \mathrm{~nm}$. This mean projected primary particle diameter, while slightly smaller than other reported values, is within the $25 \%$ standard deviation reported in the literature for primary particle size diameters (Koylu and Faeth, 1992). This value is smaller than China et al. (2013) projected primary particle diameters of $37-56 \mathrm{~nm}$, but a number of differences exist between these studies. Primarily, China et al. measured particles much larger than those examined here (aerodynamic diameters $>250 \mathrm{~nm}$ ) through use of scanning electron microscopy (SEM). Their study was also an ambient study, conducted downstream of a fire plume. The China et al. fire likely had different fuel sources and different burning conditions than those presented here. The distribution here may also be shifted to the lower end from the abundance of $10-20 \mathrm{~nm}$ primary particles that appeared mostly in the $0.9 \mathrm{fg}(50 \mathrm{~nm})$ particles from the APM. Over $80 \%$ of the primary particles observed below $20 \mathrm{~nm}$ were from $0.9 \mathrm{fg}$ agglomerates. However, primary particles below $20 \mathrm{~nm}$ only made up $40 \%$ of counts for the total number of primary particles from the $0.9 \mathrm{fg}$ agglomerates. When $<20 \mathrm{~nm}$ primary particles are omitted, the distribution of primary particle size shifts to a mean of $27 \mathrm{~nm}$. When only the particles from the $0.9 \mathrm{fg}$ agglomerates are considered, the distribution becomes a double-peaked normal distribution centered on 14 and $19 \mathrm{~nm}$.

In this study, the mean primary particle projected area and diameter shown in Fig. 3 were used in the application of Eq. (9). The analysis was applied for each of the three selected agglomerate masses from the APM. The application of mean primary projected area introduces a slight overestimation of primary particle size for the $50 \mathrm{~nm}$ agglomerates

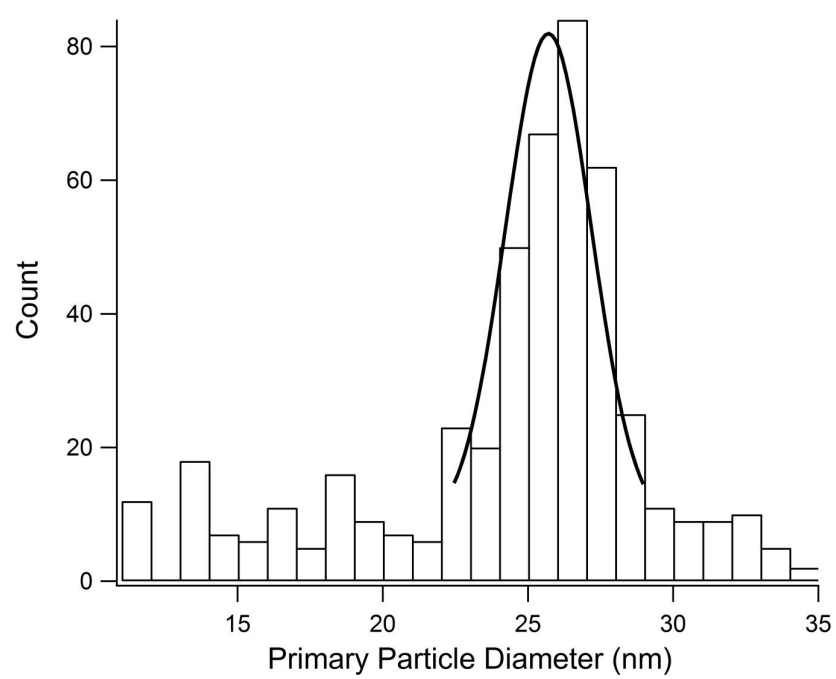

Figure 3. TEM analysis of primary particle diameters of agglomerates generated from biomass burning of chamise. Data is fit with a normal Gaussian distribution. The mean of the distribution is $25.7 \pm 2.1 \mathrm{~nm}$.

and a slight underestimation for the 75 and $100 \mathrm{~nm}$ agglomerates. However, the percent change on the calculated volume as a whole is small. For example, the bimodal $50 \mathrm{~nm}$ primary particle distribution, if half of the total agglomerate projected area is assumed to be contributed by one peak, the calculated volume is forced upward by $\sim 35 \%$. For the 75 and $100 \mathrm{~nm}$ particles, the calculated volume is forced downward by $\sim 7 \%$.

Table 1 shows the calculated application of Eqs. (8) and (9) to the TEM images obtained for the 50,75 , and $100 \mathrm{~nm}$ equivalents selected from the APM-SMPS system. Figure 4 graphically demonstrates the size dependence of the shape factor to the mobility diameter. The shape factor for these particles ranges from 1.06 to 1.42 indicating a $120-285 \%$ overestimation of the true volume of a particle when using the electrical mobility diameter.

\subsection{Morphology of aged biomass burning aerosol}

To measure the effect of atmospheric aging on biomass burning aerosol's morphology, the APM-SMPS system was used as described in Nakao et al. (2011). The TEM was not used in this section because saturation of the TEM grids required extensive time, longer than that necessary to observe changing morphology that can occur with aging.

Figure 5 shows the evolution of the fractal-like dimension $\left(D_{\mathrm{f}}^{\prime}\right)$ as a function of experimental time. In this analysis a fractal-like dimension of 3 indicates a spherical particle and $D_{\mathrm{f}}^{\prime}<3$ indicates a nonspherical particle. Calibration with ammonium sulfate, an inorganic crystalline solute and not quite spherical particle $\left(D_{\mathrm{f}}^{\prime}=2.7\right)$, is included for comparison and agrees well with previously reported literature values (Biskos et al., 2006). The black line indicates the time the UV lights 
Table 1. The number of particles analyzed from TEM images of the mobility diameters $\left(D_{\text {mobility }}\right)$ of particles selected with the APMSMPS-TEM system for freshly emitted biomass burning. Equations (7) and (8) are used to calculate the volume equivalent diameter $\left(D_{\mathrm{ve}}\right)$ and shape factor $(\chi)$.

\begin{tabular}{rrcccc}
\hline $\begin{array}{r}D_{\text {mobility }} \\
(\mathrm{nm})\end{array}$ & $\begin{array}{r}\text { Number of } \\
\text { particles } \\
\text { analyzed }\end{array}$ & $\begin{array}{c}\text { Number of primary } \\
\text { particles } \\
\text { (calculated) }\end{array}$ & $\begin{array}{c}\text { Volume of the total } \\
\text { agglomerate } \\
\left.\text { (calculated; } \mathrm{nm}^{3}\right)\end{array}$ & $\begin{array}{c}D_{\mathrm{ve}} \\
(\mathrm{nm})\end{array}$ & $\chi$ \\
\hline 50 & 42 & $6 \pm 1$ & $5.5 \times 10^{+4}$ & $47 \pm 3$ & $1.06 \pm 0.1$ \\
75 & 197 & $12 \pm 1$ & $1.1 \times 10^{+5}$ & $60 \pm 4$ & $1.25 \pm 0.1$ \\
100 & 153 & $20 \pm 2$ & $1.8 \times 10^{+5}$ & $70 \pm 8$ & $1.42 \pm 0.18$ \\
\hline
\end{tabular}

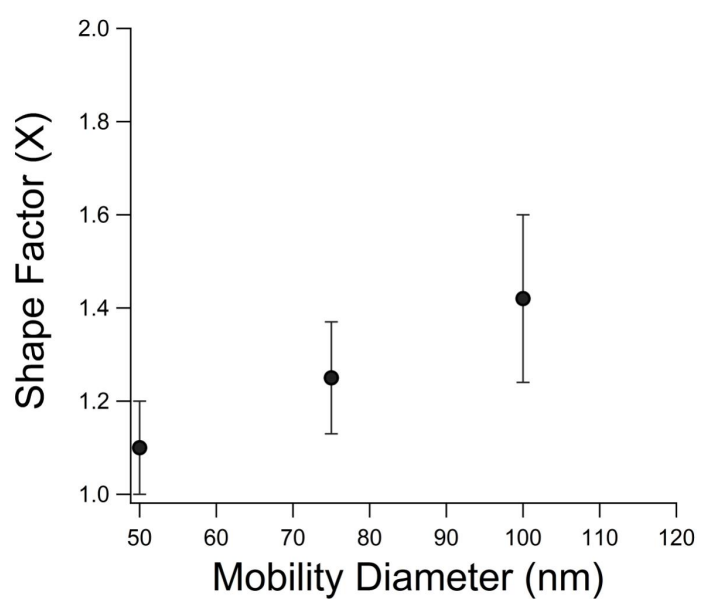

Figure 4. Shape factor $(\chi)$ vs. the APM selected mobility diameter equivalent for freshly emitted, flaming regime chamise biomass burning aerosol.

surrounding the chamber were turned on. Raw data from electrical mobility sizing and aerosol mass data are provided in supplemental material. The freshly emitted particles have a $D_{\mathrm{f}}^{\prime}$ of $2.15 \pm 0.05$ indicating a nonspherical particle, similar to the $D_{\mathrm{f}}^{\prime}$ of 2.20 of Xue et al. (2009) for freshly emitted diesel particles. After $4 \mathrm{~h}$ of photochemical exposure, the $D_{\mathrm{f}}^{\prime}$ rises nearly linearly to 2.60 .

The $D_{\mathrm{f}}^{\prime}$ analysis here is a bulk measurement of all the particles selected in the APM which increased from 50 to $250 \mathrm{~nm}$ equivalent sizes. While it should be theoretically possible to link the $D_{\mathrm{f}}^{\prime}$ reported here to the dynamic shape factor, $\chi$ (Kaspar, 1982; DeCarlo et al., 2004), we do not do so here because of the limitations an ensemble method (the APMSMPS system) has when expanded to a size-dependent individual particle analysis.

The APM-SMPS data set agrees with the TEM analysis of the previous section - that freshly emitted biomass burning aerosol are not spherical. Because the TEM operates at nearvacuum pressures, there is the possibility that volatile material may evaporate from the fractal backbone. This would skew the perceived importance of the particle's morphology. However, this second confirmation of morphology from the APM-SMPS system indicates that volatile evaporation in the

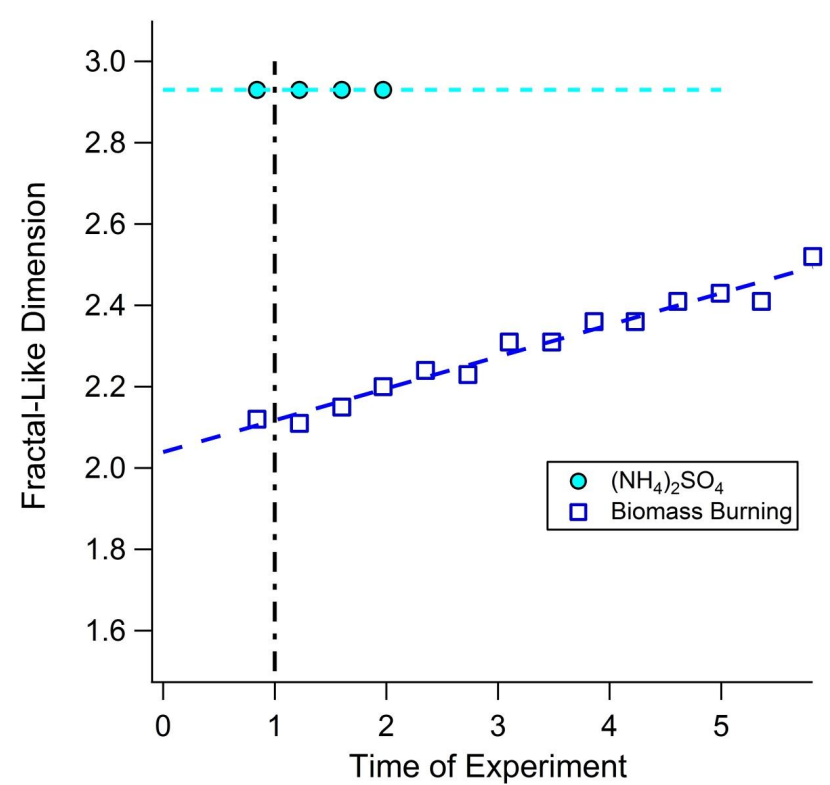

Figure 5. APM-SMPS derived fractal-like dimension data vs. time of experiment. A fractal-like dimension of 3 indicates a spherical particle, while $D_{\mathrm{f}}<3$ is nonspherical. Black line indicates time of UV lights being turned on. Ammonium sulfate calibration data is included for comparison.

TEM is not completely the reason for shape factors greater than 1 being reported.

As $D_{\mathrm{f}}^{\prime}$ increases with time, the aerosol becomes more spherical with photochemical exposure. This is likely due to a coating of SOA forming on the primary emissions (Nakao et al., 2011). The SOA fills in the void space inside the fractal agglomerates. This aged fractal-like dimension is smaller than the aged biomass burning plume aerosol measured by China et al. (2013) but the $D_{\mathrm{f}}^{\prime}$ reported here is not directly comparable to their $D_{\mathrm{f}}$. In addition to the different derivations, China et al. (2013) focused on larger particles than those investigated here, on a shorter period of atmospheric aging (1-2h), and during the smoldering phase of the burn. However, both of these results confirm, through two different methods, that applying the electrical mobility diameter as the 
volume equivalent diameter will result in an overestimation of particle size and volume.

\subsection{Applying a true volume equivalent diameter to the CCN analysis of biomass burning aerosol}

The assumption that the electrical mobility diameter cubed multiplied by $\pi / 6$ is equal to the true volume of the particle will result in a skewed $\mathrm{CCN}$ prediction for aerosol from combustion sources. The previous work of Dusek et al. (2011) has investigated conceptually the importance of fractal morphology in CCN analysis. We present experimental data for both the hygroscopicity and morphology of the particle and apply it to $\kappa$-Köhler analysis.

Figure 6 shows an example of the $\mathrm{CCN}$ to $\mathrm{CN}$ activation ratio as a function of mobility diameter for biomass burning at a supersaturation of $0.37 \%$. Both the raw electrical mobility activation diameters and the volume equivalent diameters are shown on the figure. The volume equivalent diameters are determined on a point-by-point basis by using a logarithmic regression of the data in Fig. 4 and Eq. (2). The shape factor is assumed to be equal to unity for particles smaller than $30 \mathrm{~nm}$ where the regression falls below 1 . The activation ratio of ammonium sulfate at the same supersaturation is included for comparison. Figure 6 shows the shape factor of a particle that affects its perceived mobility diameter. Since $\chi$ is greater than unity for particles larger than $30 \mathrm{~nm}$, the activation curve shifts to smaller electrical mobility diameters. In this example, the diameter where half of all particles activate $\left(D_{\mathrm{p} 50}\right)$ is measured at $75 \mathrm{~nm}$ electrical mobility but the true volume equivalent diameter for that particle is at $60 \mathrm{~nm}$.

Figure 7 shows the total effect that accounting for the volume equivalent diameter can have on the calculation of $\kappa$. The data from a nonphotochemically exposed chamise biomass burning injection into the chamber is presented. The markers in Fig. 7 are the activation diameters for each scan of the SMPS-CCNC system at a supersaturation. The red line is the $\kappa$ fit between the points as shown where the lines of constant $\kappa$ are forced such that critical supersaturation scales with $d_{\mathrm{d}}^{-3 / 2}$. The implications of this are discussed later. The black line is the fit of the points if the mobility diameter is converted to the volume equivalent diameter via the process described for Fig. 6 . The hygroscopicity of manzanita biomass, without morphological corrections, has a $\kappa$ of $0.38 \pm 0.09$. This value agrees with Engelhart et al. (2012) hygroscopicity measurements of primary (nonaged) chamise emissions. When the shape factors of the particles is taken into account using the TEM data collected concurrently, the calculated $\kappa$ increases to 0.52 . Since the particles are not spherical, their volume equivalent diameters are smaller than their mobility diameters. Therefore, using only the mobility diameter when calculating $\kappa$ can substantially underestimate hygroscopicity.

This analysis of particle morphology may help reconcile the difference in calculated hygroscopicity between filter-

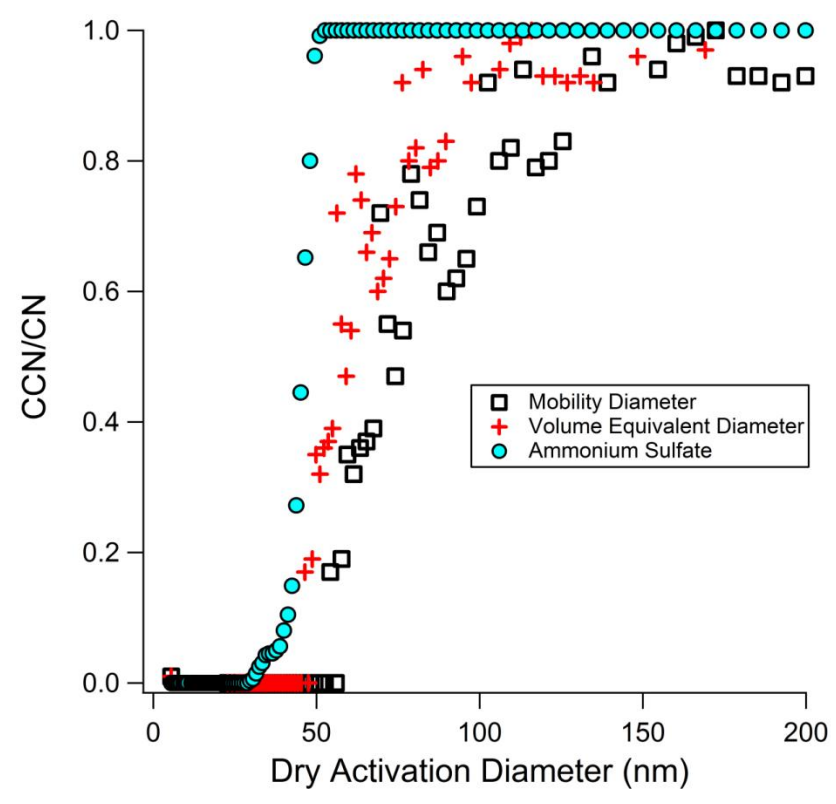

Figure 6. Activation curves for manzanita using the mobility diameter and the volume equivalent diameter calculated using the shape factor data from Fig. 4. The activation curve of ammonium sulfate is included for comparison. The black squares represent the raw electrical mobility activation diameters and the red crosses are the volume equivalent diameters.

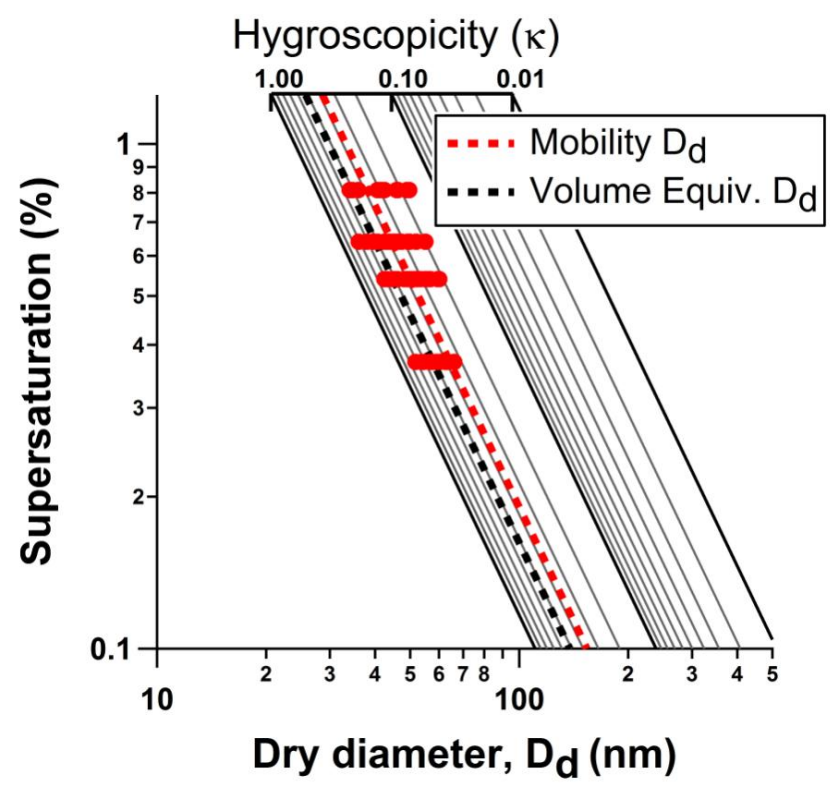

Figure 7. Supersaturation vs. the dry activation diameter for one experiment of freshly emitted chamise biomass burning aerosol. Markers indicate the data from the SMPS-CCNC system and the red line is the best-fit $\kappa$ between the points. The black line indicates the $\kappa$ when the volume equivalent diameter is used instead of the mobility diameter. 
reconstituted biomass burning aerosol and in situ sampled aerosol. Carrico et al. (2008) reported H-TDMA (hygroscopicity tandem differential mobility analyzer) and CCN-derived $\kappa$ values for biomass burning filter samples extracted in water and methanol. The $\mathrm{CCN}$-derived $\kappa$ from the Carrico et al. study of Alaskan duff core aerosol extracted in water was 0.148 . This value is significantly higher than the online sampling of Alaskan duff core done by both Petters et al. (2009) and Engelhart et al. (2012) which reported a CCNderived $\kappa$ value of 0.09 and 0.07 , respectively. Despite the fact that Petters et al. (2009) humidified and dried their particles (up to $>95 \% \mathrm{RH}$ (relative humidity) and then down to $<5 \% \mathrm{RH}$ ), there still exists a large discrepancy between humidified/dehumidified particles and the filter-reconstituted aerosol. The $50 \%$ increase in filter-reconstituted hygroscopicity may be due to the use of mobility diameter as the volume equivalent diameter for nonspherical aerosols. In filter reconstitution, the liquid solution is first atomized and dried before flowing into the downstream instruments. The process of drying may fill in void space in a nonspherical backbone; thus, producing a particle whose volume equivalent and electrical mobility diameters are identical. It is important to note that Carrico et al. (2008) reported a lower hygroscopicity value for reconstituted sagebrush than both Petters et al. (2009) and Engelhart et al. (2012) in situ sampled aerosol, though Petters et al. humidified and dehumidified their aerosol. This discrepancy may be due to different burning or feedstock conditions that may influence particle composition. Additionally, the Petters et al. (2009) hygroscopicity results must be viewed alongside the Martin et al. (2013) work on particle prehumidification. The work presented here clearly shows that particles with mobility diameters between 50 and $100 \mathrm{~nm}$ are not spherical. However, Martin et al. was unable to collapse particles below mobility diameters of $100 \mathrm{~nm}$ with exposure to high relative humidity. The Martin et al. result may suggest that there is a lower limit for particle shape factor for which a particle exposed to subsaturated conditions can collapse. If such a limit exists, then the Petters et al. humidification of the particles would not affect any comparisons between in situ sampled aerosols and filter-reconstituted aerosols (due to the activation diameters of Petters' aerosols). Since reconstitution of aerosols appears to increase measured hygroscopicity, this also suggests that cloud processing of fractal aerosols should be considered for biomass burning aerosol's climate impacts.

\subsection{Sensitivity of $\kappa$ to particle shape factor}

Because the shape factor of particles derived from biomass burning can range from 1 to greater than 1.5, the importance of particle morphology can be negligible to substantial.

While the current literature on the morphology of biomass burning aerosols is sparse, the work done on diesel particles suggests that burn conditions may play a part in particle morphology (Park et al., 2004; Nakao et al., 2011). Along with

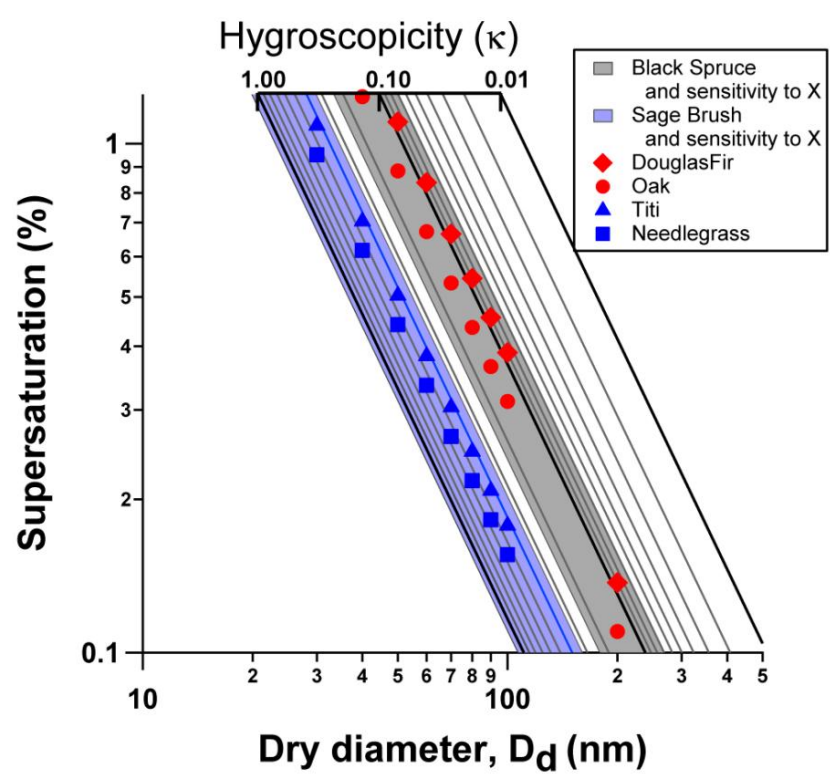

Figure 8. Sensitivity analysis of $\kappa$ to $\chi . \kappa$ data for each biomass burning species is taken from Petters et al. (2009). The sensitivity of $\kappa$ to $\chi$ is analyzed using two constant dynamic shape factors of $1-1.5$. The region between the two $\chi$ values is shaded in grey for black spruce and blue for sage brush. The $\kappa$ lines for Douglas fir, oak, titi, and needlegrass rush are shown for comparison.

the effects that particle aging have on morphology shown in this study, it is prudent to analyze the potential range of hygroscopicities that biomass burning aerosols can have.

For any nonspherical, fractal particle generated from combustion, the larger the activation diameter in a CCNC, the greater the difference between the mobility diameter and volume equivalent diameter will be. Figure 8 shows how sensitive $\kappa$ can be when applying a volume equivalent diameter calculation. In Fig. 8, hygroscopicity data from biomass burning tests by Petters et al. (2009) is used. The grey-shaded area is the sensitivity of black spruce $(\kappa=0.07)$ when applying a dynamic shape factor of 1 (right-most boundary of the shaded area) and of 1.5 (left-most boundary of the shaded area). Here, black spruce ranges from a $\kappa$ of 0.07 to 0.24 . The blue-shaded area is the same treatment for sage brush ( $\kappa=0.33-1.1$ after applying $\chi$ ). The hygroscopicity values of Petters et al. (2009) are used here despite their humidified conditioning. The values from Petters et al. used here are the averages for both their stack and chamber burns which represent a large range of hygroscopicities over a number of burns. It should be noted that their humidification and drying of the particle may collapse the particle to a sphere. However, the average values they report seem to fall within the range of biomass burning hygroscopicity values that subsequent groups have reported without the humidification step (e.g., Hennigan et al., 2011; Engelhart et al., 2012; Giordano et al., 2013). Douglas fir, oak, titi, and needlegrass, two relatively low-hygroscopic and two moderately hygroscopic biomass 
burning species, are included for comparison. In this analysis we apply a constant shape factor across all diameters as opposed to the mobility diameter-dependent treatment used earlier. This sensitivity analysis therefore shows the area in which the true $\kappa$ line falls in but not necessarily its slope. It is also a large range of $\chi$ which captures the effects that burn conditions and the species itself may have on particle morphology. This range is indicative of the effects that photochemical aging can have on morphology.

It is worth noting that a $\kappa$ value of 1.1 is higher than that of pure potassium chloride $(\kappa=0.99)$ and is likely an unreasonable hygroscopicity value to use for biomass burning aerosol (Carrico et al., 2010). The high hygroscopicity value comes out of the application of the extreme shape factor value of $\chi=1.5$. In application, a more realistic median or even minimum $\chi$ should likely be applied when calculating particle hygroscopicity.

A sensitivity analysis of how the slip correction factor affects $\kappa$ can also be performed. The analysis can be performed using Eqs. (1), (2), and (3) at a constant supersaturation and applying a range of $\chi$ from 1.01 to 1.5 at standard temperature and pressure. The percent underestimation of $\kappa$ over the range of shape factors is nearly linear. At $\chi=1.01, \kappa$ is underestimated by $1.66 \%$ and at $\chi=1.5, \kappa$ is underestimated by $47.5 \%$. Even when applying a large shape factor $(\chi=1.5)$, the percent difference between the Cunningham slip correction factor at the mobility diameter compared to the volume equivalent diameter is only approximately $17 \%$. At lower shape factors $(\chi=1.01)$, the difference is even more negligible.

Figure 9 shows the sensitivity of the slope of the $\kappa$-Köhler isolines (heretofore referred to as the experimental exponent or exponent) to two different methods of applying the shape factor to CCN analysis. Shown in the figure is the application of a constant shape factor $\left(\chi \neq f\left(d_{\text {dry }}\right)\right)$ and a variable shape factor $\left(\chi=f\left(d_{\text {dry }}\right)\right)$. The data shown is an interpolation of the $\kappa$ data from the chamise experiments shown in Fig. 7. The constant application of $\chi$ does not exhibit any change in the experimental exponent of the $\kappa$ lines. $S_{\mathrm{c}}$ scales with $d_{\mathrm{d}}^{-3 / 2}$ as predicted by Köhler theory. This suggests that the solute dissolution process is thermodynamically ideal, the particle completely dissolves and surface tension effects are negligible. When a variable shape factor is applied, $s_{\mathrm{c}}$ then scales with $d_{\mathrm{d}}^{-1.8}$. Kumar et al. (2011) observed a similar effect on the $\kappa$ exponent in wet processed soil and dust samples. Their study observed an unusually low experimental exponent of -2.16 for the wet processed mineral sample, Arizona test dust (ATD). This deviation from Köhler theory could be caused by sparingly soluble species, an externally mixed sample (composition as a function of particle size), or activation physics. While the droplet formation mechanisms between ATD and biomass burning aerosol are likely different (adsorption vs. absorption), the presence of sparingly soluble species could explain the deviation from Köhler theory

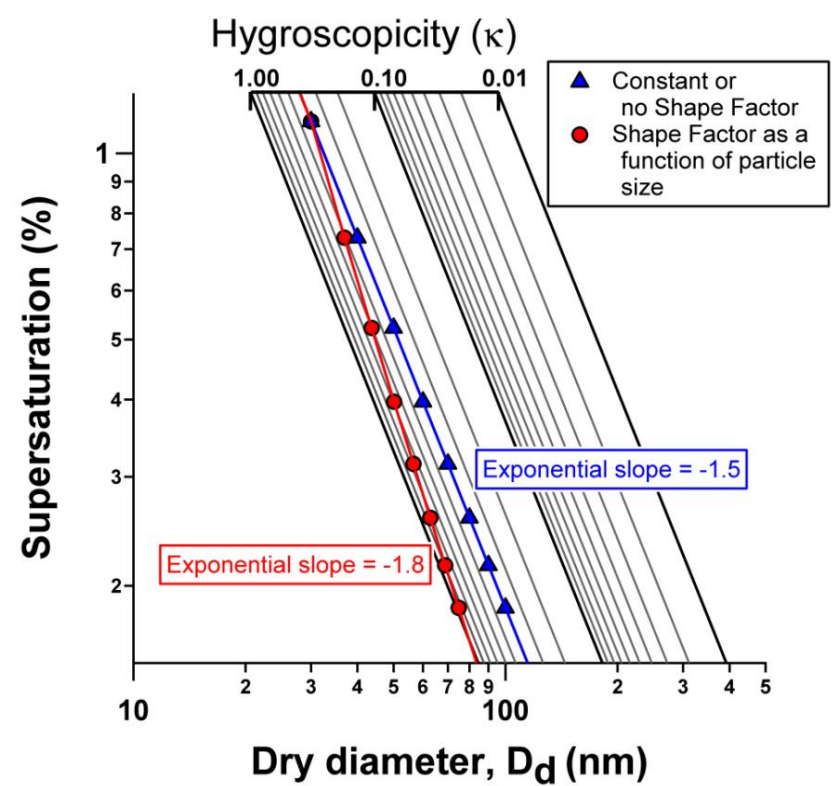

Figure 9. Variation of $\kappa$-Köhler isolines when applying a constantor no-shape factor and applying a shape factor as a function of particle size. The blue triangles have a critical supersaturation that scales with $d_{\mathrm{d}}^{-3 / 2}$ due to a constant shape factor being applied while the red circles scale with $d_{\mathrm{d}}^{-1.8}$ due to the $\chi-d_{\text {mobility }}$ relationship from Fig. 4 being applied.

for the corrected data set of combustion aerosol. Further investigation into this phenomenon is required. The complexity and non-ideal behavior of the aerosol solute can be masked if electrical mobility diameter is used in $\mathrm{CCN}$ analysis.

\section{Conclusions}

This work investigated the morphology and hygroscopicity of biomass burning aerosol. We show, through two independent measurements that particles emitted from biomass combustion are not spherical and that the degree of nonsphericity can change with photochemical exposure. Thus, for biomass burning aerosol sampled near source with electrical mobility techniques, size and volume measurements are likely overestimated. As the aging process occurs, SOA condenses on the fractal particle and the volume changes (measured through electrical mobility) are small compared to changes in particle mass. We also measure the dynamic shape factor of freshly emitted particles and apply it to $\kappa$-Köhler theory to accurately determine the volume of particles activating into droplets. We find that particle morphology is a function of a particle's electrical mobility diameter, which is consistent with the literature, and a particle's dynamic shape factor can range from 1.06 to 1.42 for electrical mobility equivalent diameters of $50-100 \mathrm{~nm}$. These mobility diameters are relevant for $\mathrm{CCN}$ activation and therefore represent an underestimation of $\kappa$ since the volume of particle that is being activated 
is smaller than assumed. Alone, this suggests an underestimation of up to almost $50 \%$. The uncertainty induced by excluding particle morphology in $\mathrm{CCN}$ data sets is consistent with the range of biomass burning $\kappa$ values presented in literature data. The issue of parameterizing particle hygroscopicity is further complicated by changes in particle morphology and composition that occur with photochemical aging and time. Biomass burning derived aerosols, from a number of biomass species including manzanita and chamise, experience a decrease in hygroscopicity with aging (Engelhart et al., 2012; Giordano et al., 2013). The results presented here suggest that morphological changes as well as chemical compositional changes may contribute to that phenomenon. A number of questions still remain to be investigated about the true nature of biomass hygroscopicity. Since shape factor, $\chi$, is a function of particle size, in practice this means that the $\kappa$ isolines do not follow those of an ideal solution, where critical supersaturation scales with $d_{\mathrm{d}}^{-3 / 2}$. Scaling with ideal theory suggests that critical solubility and surface tension limits are negligible and thus non-ideal effects are partially hidden from electrical mobility-CCNC observation. The corrected data suggests that $s_{\mathrm{c}}$ scales with $d_{\mathrm{d}}^{-1.8}$ and does not follow ideal thermodynamic behavior. Non-ideal behavior is observed because the process of chemical transformation (secondary aerosol formation) occurs concurrently with the physical rounding (decrease in the fractal nature) of the particles. The importance of timescales for chemical vs. physical evolution of ambient biomass burning aerosols needs to be further explored. 


\section{Appendix A}

Table A1. $\left(\mathrm{NH}_{4}\right)_{2} \mathrm{SO}_{4}$ DMT CCN calibration information for a $0.5 \mathrm{~L} \mathrm{~min}^{-1}$ flow rate.

\begin{tabular}{cccc}
\hline Supersaturation setting $(\%)$ & $\Delta T\left({ }^{\circ} \mathrm{C}\right)$ & $D_{\mathrm{d}}(\mathrm{nm})$ & Supersaturation reported \\
\hline 0.2 & 4.6 & 81.0 & $0.20 \%$ \\
0.4 & 7.6 & 54.81 & $0.37 \%$ \\
0.6 & 10.6 & 42.2 & $0.54 \%$ \\
0.8 & 13.6 & 37.3 & $0.64 \%$ \\
1.0 & 16.5 & 32.05 & $0.81 \%$ \\
\hline
\end{tabular}

Table A2. Summary and definition of key symbols.

\begin{tabular}{lll}
\hline Symbol & Meaning & Reference \\
\hline$\kappa$ & Hygroscopicity parameter & Petters and Kreidenweis (2007) \\
$\chi$ & Dynamic shape factor & Kaspar (1982); DeCarlo et al. (2004) and references therein \\
$D_{\mathrm{d}}$ & $\begin{array}{l}\text { Activation diameter of a dry particle at a given supersaturation } \\
\text { used in the } \kappa \text {-Köhler hygroscopicity parameterization }\end{array}$ & Petters and Kreidenweis (2007) \\
$D_{\mathrm{m}}$ & Electrical mobility diameter of a dry particle & DeCarlo et al. (2004) and references therein \\
$D_{\mathrm{ve}}$ & Volume equivalent diameter of a dry particle & DeCarlo et al. (2004) and references therein \\
$N$ & Number of primary particles in an aggregate & Oh and Sorensen (1997) and references therein \\
$A_{\mathrm{p}}$ & Mean projected area of primary particles & Oh and Sorensen (1997) and references therein \\
$A_{\mathrm{a}}$ & Projected area of an agglomerate & Oh and Sorensen, 1997 and references therein \\
$k_{\mathrm{a}}, \alpha$ & Empirical factors used to calculate the number of & Oh and Sorensen (1997) and references therein \\
& primary particles in an aggregate from a projection & \\
\hline
\end{tabular}

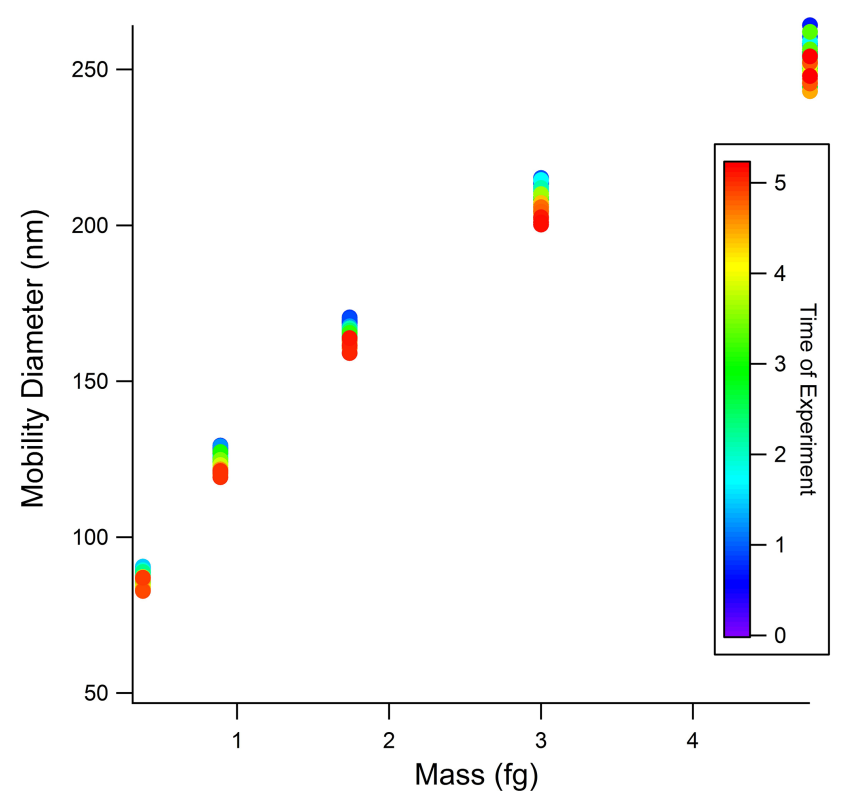

Figure A1. Raw APM-SMPS data for one chamise experiment shown in the paper. The mobility diameter for a number of selected particle masses is shown with plot markers colored as a function of experiment time. Lights are turned on at time $=1$. Decreasing measured mobility diameter for a given particle mass indicates that particles are becoming less fractal with time. 
Acknowledgements. Many thanks to David Weise and Joey Chong of the USDA Forest Service for their advice and pivotal role in the acquisition of fuels. The authors would also like to thank David Cocker and the Keck Foundation for use of the environmental chamber. M. Giordano would also like to thank Bibiana Lopez for her work supporting this paper. M. Giordano would like to thank the California NASA Space Grant Consortium for partially supporting this work. M. Giordano and A. Asa-Awaku would also like to thank the US Environmental Protection Agency for funding this work made possible by EPA grant number 83504001. Any opinions, findings, and conclusions expressed in this material are those of the authors and do not necessarily reflect the views of the NSF, NASA, or EPA.

Edited by: V. F. McNeill

\section{References}

Allen, M. D. and Raabe, O. G.: Reevaluation of Millikan's oil drop data for the motion of small particles in air, J. Aerosol Sci., 13, 537-547, 1982.

Andreae, M. O., Rosenfeld, D., Artaxo, P., Costa, A. A., Frank, G. P., Longo, K. M., and Silva-Dias, M. A. F.: Smoking rain clouds over the Amazon, Science, 303, 1337-1342, doi:10.1126/science.1092779, 2004.

Baron, P. A. and Willeke, K.: Aerosol measurement. Principles, Techniques and Applications, Second Edn., Wiley Interscience, New York, 2001.

Baron, P. A., Sorensen, C. M., and Brockmann. J. E.: Nonspherical particle measurements: Shape factors, fractals, and fibers, in: Aerosol Measurement: Principles. Techniques. and Applications, edited by: Baron, P. A. and Willeke, K., John Wiley, New York, 705-749, 2001.

Biskos, G., Paulsen, D., Russell, L. M., Buseck, P. R., and Martin, S. T.: Prompt deliquescence and efflorescence of aerosol nanoparticles, Atmos. Chem. Phys., 6, 4633-4642, doi:10.5194/acp-64633-2006, 2006.

Carrico, C. M., Petters, M. D., Kreidenweis, S. M., Collett Jr., J. L., Engling, G., and Malm, W. C.: Aerosol hygroscopicity and cloud droplet activation of extracts of filters from biomass burning experiments, J. Geophys. Res., 113, D08206, doi:10.1029/2007JD009274, 2008.

Carrico, C. M., Petters, M. D., Kreidenweis, S. M., Sullivan, A. P., McMeeking, G. R., Levin, E. J. T., Engling, G., Malm, W. C., and Collett Jr., J. L.: Water uptake and chemical composition of fresh aerosols generated in open burning of biomass, Atmos. Chem. Phys., 10, 5165-5178, doi:10.5194/acp-10-5165-2010, 2010.

China, S., Mazzoleni, C., Gorkowski, K., Aiken, A. C., and Dubey, M. K.: Morphology and mixing state of individual freshly emitted wildfire carbonaceous particles, Nature Communications, 4 , 2122, doi:10.1038/ncomms3122, 2013.

Crutzen, P. J. and Andreae, M. O.: Biomass burning in the tropics: Impact on atmospheric chemistry and biogeochemical cycles, Science, 250, 1669-1678, doi:10.1126/science.250.4988.1669, 1990.

Dahneke, B.: Slip correction factors for nonspherical bodies-I Introduction and continuum flow, J. Aerosol Sci., 4, 139-145, 1973 a.
Dahneke, B.: Slip correction factors for nonspherical bodies-II Free molecule flow, J. Aerosol Sci., 4,147-161, 1973b.

DeCarlo, P. F., Slowik, J. G., Worsnop, D. R. Davidovits, P., and Jimenez, J. L.: Particle morphology and density characterization by combined mobility and aero- dynamic diameter measurements. Part 1: Theory, Aerosol Sci. Tech., 38, 1185-1205, 2004.

Dusek, U., Frank, G. P., Massling, A., Zeromskiene, K., Iinuma, Y., Schmid, O., Helas, G., Hennig, T., Wiedensohler, A., and Andreae, M. O.: Water uptake by biomass burning aerosol at suband supersaturated conditions: closure studies and implications for the role of organics, Atmos. Chem. Phys., 11, 9519-9532, doi:10.5194/acp-11-9519-2011, 2011.

Engelhart, G. J., Hennigan, C. J., Miracolo, M. A., Robinson, A. L., and Pandis, S. N.: Cloud condensation nuclei activity of fresh primary and aged biomass burning aerosol, Atmos. Chem. Phys., 12, 7285-7293, doi:10.5194/acp-12-7285-2012, 2012.

Forster, P., Ramaswamy, V., Artaxo, P., Berntsen, T., Betts, R., Fahey, D. W., Haywood, J., Lean, J., Lowe, D. C., Myhre, G., Nganga, J., Prinn, R., Raga, G., Schulz, M., and Van Dorland, R.: Changes in Atmospheric Constituents and in Radiative Forcing, in: Climate Change 2007: The Physical Science Basis. Con tribution of Working Group I to the Fourth Assessment Report of the Intergovernmental Panel on Climate Change, edited by: Solomon, S., Qin, D., Manning, M., Chen, Z., Marquis, M., Averyt, K. B., Tignor, M., and Miller, H. L., Cambridge University Press, Cambridge, UK and New York, NY, USA, 2007.

Fuchs, N. A.: The Mechanics of aerosols, Pergamon, New York, ISBN-10: 008010066X, 1964.

Giordano, M. R., Short, D. Z., Hosseini, S., Lichtenberg, W., and Asa-Awuku, A.: Changes in droplet surface tension affect the observed hygroscopicity of photochemically aged biomass burning aerosol, Environ. Sci. Technol., 47, 10980-10986, doi:10.1021/es401867j, 2013.

Haywood, J. and Boucher, O.: Estimates of the direct and indirect radiative forcing due to tropospheric aerosols: A review, Rev. Geophys., 38, 513-543, 2000.

Hennigan, C. J., Miracolo, M. A., Engelhart, G. J., May, A. A., Presto, A. A., Lee, T., Sullivan, A. P., McMeeking, G. R., Coe, H., Wold, C. E., Hao, W.-M., Gilman, J. B., Kuster, W. C., de Gouw, J., Schichtel, B. A., Collett Jr., J. L., Kreidenweis, S. M., and Robinson, A. L.: Chemical and physical transformations of organic aerosol from the photo-oxidation of open biomass burning emissions in an environmental chamber, Atmos. Chem. Phys., 11, 7669-7686, doi:10.5194/acp-11-7669-2011, 2011.

Kaspar, G.: Dynamics and measurement of smokes. I. Size characterization of non-spherical particles, Aerosol Sci. Tech., 1, 187199, 1982.

Khalizov, A. F., Zhang, R., Zhang, D., Xue, H., Pagels, J., and McMurry, P. H.: Formation of highly hygroscopic soot aerosols upon internal mixing with sulfuric acid vapor, J. Geophys. Res., 114, D05208, doi:10.1029/2008JD010595, 2009.

Knutson, E. O. and Whitby, K. T.: Aerosol classification by electric mobility: apparatus, theory, and applications, J. Aerosol Sci., 6, 443-451, doi:10.1016/0021-8502(75)90060-9, 1975.

Kousaka, Y., Endo, Y., Ichitsubo, H., and Alonso, M.: Orientationspecific dynamic shape factors for doublets and triplets of spheres in the transition regime, Aerosol Sci. Tech., 24, 36-44, 1996. 
Koylu, U. O., and Faeth, G. M.: Structure of overfire soot in buoyant turbulent diffusion flames at long residence times, Combust. Flame, 89, 140-156, 1992.

Koylu, U. O., Faeth, G. M., Farias, T. L., and Carvalho, M. G.: Fractal and projected structure properties of soot aggregates, Combust. Flame, 100, 621-633, 1995.

Kumar, P., Sokolik, I. N., and Nenes, A.: Cloud condensation nuclei activity and droplet activation kinetics of wet processed regional dust samples and minerals, Atmos. Chem. Phys., 11, 8661-8676, doi:10.5194/acp-11-8661-2011, 2011.

Kuwata, M. and Kondo, Y.: Measurements of particle masses of inorganic salt particles for calibration of cloud condensation nuclei counters, Atmos. Chem. Phys., 9, 5921-5932, doi:10.5194/acp9-5921-2009, 2009.

Lathem, T. L., Beyersdorf, A. J., Thornhill, K. L., Winstead, E. L., Cubison, M. J., Hecobian, A., Jimenez, J. L., Weber, R. J., Anderson, B. E., and Nenes, A.: Analysis of CCN activity of Arctic aerosol and Canadian biomass burning during summer 2008, Atmos. Chem. Phys., 13, 2735-2756, doi:10.5194/acp-13-27352013, 2013.

Lee, K. O., Cole, R., Sekar, R., Choi, M. Y., Zhu, J., Kang J., and Bae, C.: Detailed characterization of morphology and dimensions of diesel particulates via thermophoretic sampling, SAE Technical Paper Series 2001-01-3572, 2001.

Liu, X. and Wang, J.: How important is organic aerosol hygroscopicity to aerosol indirect forcing?, Environ. Res. Lett., 5, 044010, doi:10.1088/1748-9326/5/4/044010, 2010.

Malloy, Q. G. J., Nakao, S., Qi, L., Austin, R., Stothers, C., Hagino, H., and Cocker III, D. R.: Real-time aerosol density determination utilizing a modified scanning mobility particle sizer-aerosol particle mass analyzer system, Aerosol Sci. Tech., 43, 673-678, doi:10.1080/02786820902832960, 2009.

Mandelbrot, B.: The Fractal Geometry of Nature, W. H. Freeman and Co., New York, 1982.

Martin, M., Tritscher, T., Jurányi, Z., Heringa, M. F., Sierau, B., Weingartner, E., Chirico, R., Gysel, M., Prévôt, A. S. H., Baltensperger, U., and Lohmann, U.: Hygroscopic properties of fresh and aged wood burning particles, J. Aerosol Sci., 56, 1529, 2013.

Martins, J. A., Gonçalves, F. L. T., Morales, C. A., Fisch, G. F., Pinheiro, F. G. M., Júnior, J. B. V. L., and Dias, M. A. F. S.: Cloud condensation nuclei from biomass burning during the Amazonian dry-to-wet transition season, Meteorol. Atmos. Phys., 104, 83-93, 2009.

McMurry, P. H., Wang. X., Park, K., and Ebara, K.: The relationship between mass and mobility for atmospheric particles: A new technique for measuring particle density, Aerosol Sci. Tech., 36, 227-238, 2002.

Meakin, P., Donn, B., and Mulholland, G. W.: Collisions between point masses and fractal aggregates, Langmuir, 5, 510-518, 1989.

Moore, R. H., Nenes, A., and Medina, J.: Scanning mobility CCN analysis - a method for fast measurements of size-resolved CCN distributions and activation kinetics, Aerosol Sci. Tech., 44, 861871, doi:10.1080/02786826.2010.498715, 2010.

Nakao, S., Shrivastava, M., Nguyen, A., Jung, H., and Cocker III, D.: Interpretation of secondary organic aerosol formation from diesel exhaust photooxidation in an en- vironmental chamber, Aerosol Sci. Tech., 45, 964-972, doi:10.1080/02786826.2011.573510, 2011.

Novakov, T. and Corrigan, C. E.: Cloud condensation nucleus activity of the organic component of biomass smoke particles, Geophys. Res. Lett., 23, 2141-2144, 1996.

Oh, C. and Sorensen, C. M. The Effect of overlap between monomers on the determination of fractal cluster morphology, J. Colloid Interf. Sci., 193, 17-25, 1997.

Park, K., Cao, F., Kittelson, D. B., and McMurry, P. H.: Relationship between particle mass and mobility for diesel exhaust particles, Environ. Sci. Technol., 37, 577-583, 2003.

Park, K., Kittelson, D. B., and McMurry, P. H.: Structural properties of diesel exhaust particles measured by transmission electron microscopy (TEM): Relationships to particle mass and mobility, Aerosol Sci. Tech., 38, 881-889, doi:10.1080/027868290505189, 2004.

Petters, M. D. and Kreidenweis, S. M.: A single parameter representation of hygroscopic growth and cloud condensation nucleus activity, Atmos. Chem. Phys., 7, 1961-1971, doi:10.5194/acp-71961-2007, 2007.

Petters, M. D., Carrico, C. M., Kreidenweis, S. M., Prenni, A. J., DeMott, P. J., Collett, J. L., and Moosmüller, H.: Cloud condensation nucleation activity of biomass burning aerosol, J. Geophys. Res., 114, D22205, doi:10.1029/2009JD012353, 2009.

Pöschl, U.: Atmospheric aerosols: Composition, transformation, climate and health effects, Angew. Chem. Int. Edit., 44, 7520 7540, 2005.

Ramanathan, V., Crutzen, P. J., Kiehl, J. T., and Rosenfeld, D.: Aerosols, climate, and the hydrological cycle, Science, 294, 2119-2124, 2001.

Raymond, T. M. and Pandis, S. N.: Cloud activation ofsinglecomponent organic aerosol particles, J. Geophys. Res., 107, 4787, doi:10.1029/2002JD002159, 2002.

Reid, J. S., Koppmann, R., Eck, T. F., and Eleuterio, D. P.: A review of biomass burning emissions part II: intensive physical properties of biomass burning particles, Atmos. Chem. Phys., 5, 799825, doi:10.5194/acp-5-799-2005, 2005.

Reutter, P., Su, H., Trentmann, J., Simmel, M., Rose, D., Gunthe, S. S., Wernli, H., Andreae, M. O., and Pöschl, U.: Aerosol- and updraft-limited regimes of cloud droplet formation: influence of particle number, size and hygroscopicity on the activation of cloud condensation nuclei (CCN), Atmos. Chem. Phys., 9, 70677080, doi:10.5194/acp-9-7067-2009, 2009.

Roberts, G. C. and Nenes, A.: A continuous-flow streamwise thermal-gradient $\mathrm{CCN}$ chamber for atmospheric measurements, Aerosol Sci. Tech., 39, 206-221, doi:10.1080/027868290913988, 2005.

Rose, D., Gunthe, S. S., Mikhailov, E., Frank, G. P., Dusek, U., Andreae, M. O., and Pöschl, U.: Calibration and measurement uncertainties of a continuous-flow cloud condensation nuclei counter (DMT-CCNC): CCN activation of ammonium sulfate and sodium chloride aerosol particles in theory and experiment, Atmos. Chem. Phys., 8, 1153-1179, doi:10.5194/acp-8-11532008, 2008.

Rose, D., Nowak, A., Achtert, P., Wiedensohler, A., Hu, M., Shao, M., Zhang, Y., Andreae, M. O., and Pöschl, U.: Cloud condensation nuclei in polluted air and biomass burning smoke near the mega-city Guangzhou, China - Part 1: Size-resolved measurements and implications for the modeling of aerosol particle hy- 
groscopicity and CCN activity, Atmos. Chem. Phys., 10, 33653383, doi:10.5194/acp-10-3365-2010, 2010.

Rose, D., Gunthe, S. S., Su, H., Garland, R. M., Yang, H., Berghof, M., Cheng, Y. F., Wehner, B., Achtert, P., Nowak, A., Wiedensohler, A., Takegawa, N., Kondo, Y., Hu, M., Zhang, Y., Andreae, M. O., and Pöschl, U.: Cloud condensation nuclei in polluted air and biomass burning smoke near the mega-city Guangzhou, China - Part 2: Size-resolved aerosol chemical composition, diurnal cycles, and externally mixed weakly $\mathrm{CCN}$-active soot particles, Atmos. Chem. Phys., 11, 2817-2836, doi:10.5194/acp-112817-2011, 2011.

Schmidt-Ott, A., Baltensperger, U., Gaggeler, H. W., and Jost, D. T.: Scaling behavior of physical parameters describing agglomerates, J. Aerosol Sci., 21, 711-717, 1990.

Seaton, A., Godden, D., MacNee, W., and Donaldson, K.: Particulate air pollution and acute health effects, The Lancet, 345, 176178, 1995.

Seinfeld, J. H. and Pandis, S. N.: Atmospheric Chemistry and Physics: From air pollution to climate change, 2nd Edn., John Wiley and Sons, Hoboken, NJ, 2006.

Shulman, M. L., Jacobson, M. C., Carlson, R. J., Synovec, R. E., and Young, T. E.: Dissolution behavior and surface tension effects of organic compounds in nucleating cloud droplets, Geophys. Res. Lett., 23, 277-280, 1996.

van der Werf, G. R., Randerson, J. T., Giglio, L., Collatz, G. J., Kasibhatla, P. S., and Arellano Jr., A. F.: Interannual variability in global biomass burning emissions from 1997 to 2004, Atmos. Chem. Phys., 6, 3423-3441, doi:10.5194/acp-6-3423-2006, 2006.
Ward, D. E. and Hao, W. M.: Projections of emissions from burning of biomass for use in studies of global climate and atmospheric chemistry, Proceedings of the 84th Annual Meeting and Exhibition Air \& Waste Management Association, Volume 19, 16-21 June 1991, Vancouver, British Colombia, Canada, 1993.

Xue, H., Khalizov, A. F., Wang, L., Zheng, J., and Zhang, R.: Effects of coating of dicarboxylic acids on the mass-mobility relationship of soot particles, Environ. Sci. Technol., 43, 2787-2792, 2009.

Yokelson, R. J., Crounse, J. D., DeCarlo, P. F., Karl, T., Urbanski, S., Atlas, E., Campos, T., Shinozuka, Y., Kapustin, V., Clarke, A. D., Weinheimer, A., Knapp, D. J., Montzka, D. D., Holloway, J., Weibring, P., Flocke, F., Zheng, W., Toohey, D., Wennberg, P. O., Wiedinmyer, C., Mauldin, L., Fried, A., Richter, D., Walega, J., Jimenez, J. L., Adachi, K., Buseck, P. R., Hall, S. R., and Shetter, R.: Emissions from biomass burning in the Yucatan, Atmos. Chem. Phys., 9, 5785-5812, doi:10.5194/acp-9-5785-2009, 2009.

Zhang, R., Khalizov, A. F., Pagels, J., Zhang, D., Xue, H., and McMurry, P. H.: Variability in morphology, hygroscopicity, and optical properties of soot aerosols during atmospheric processing, P. Natl. Acad. Sci. USA, 105, 10291-10296, doi:10.1073/pnas.0804860105, 2008. 